\title{
The Evaluation of Laser Application in Surgery: A Review Article
}

\author{
Ensieh Khalkhal ${ }^{1}$, Majid Rezaei-Tavirani ${ }^{2}$, Mohammad Reza Zali ${ }^{3}$, Zahra Akbari ${ }^{4}$ \\ ${ }^{1}$ Proteomics Research Center, Faculty of Paramedical Sciences, Shahid Beheshti University of Medical Sciences, Tehran, \\ Iran \\ ${ }^{2}$ Faculty of Medicine, Iran University of Medical Sciences, Tehran, Iran \\ ${ }^{3}$ Gastroenterology and Liver Diseases Research Center, Research Institute for Gastroenterology and Liver Diseases, Shahid \\ Beheshti University of Medical Sciences, Tehran, Iran \\ ${ }^{4}$ Laser Application in Medical Sciences Research Center, Shahid Beheshti University of Medical Sciences, Tehran, Iran
}

\section{*Correspondence to Majid Rezaei-Tavirani, Firoozabadi Hospital, Fadayan- e-Eslam, District 20, Tehran Province, Tehran. Tel.+980215104 8000; Email: tavirani_m@yahoo.com}

Published online December 1 , 2019

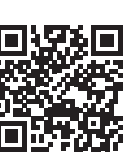

\begin{abstract}
There are several types of surgeries which use lasers in the operating room. Surgeons use lasers in general surgery or surgical specialties to cut, coagulate, and remove tissue. In modern medicine, the application of laser therapy is an attractive subject due to its minimal invasive effect. Today lasers are widely used in the treatment and diagnosis of many diseases such as various cancers, lithotripsy, ophthalmology, as well as dermatology and beauty procedures. Depending on the type of lasers, the wavelength and the delivery system, most lasers have replaced conventional surgical instruments for better wound healing results. Over time, by using many different tools and devices, new lasers have been created; as a result, they are used in a wide range of medical special cases. In this review, laser applications in surgery and its beneficial effects compared to previous surgeries with the aim of providing appropriate therapeutic and non-invasive solutions with minimal side effects after surgery are investigated.
\end{abstract}

Keywords: Surgery; Laser; Benefit.

\section{Introduction}

Laser surgery is a kind of surgery which makes use of the laser beam cutting power to obtain bloodless cuts in tissue or eliminate a superficial lesion such as a skin tumor. Today there is an increased interest in minimally invasive surgery. ${ }^{1}$ In other surgery areas, the techniques have been refined, in which no or smaller incisions are required. There are many types of lasers that are different in emitted light wavelengths and their power and ability to clot, cut or vaporize tissue. Lasers are used to relieve bleeding or obstruction of some diseases. Lasers are applied to shrink or destroy and eliminate colon polyps and tumors that have intestinal or gastric obstruction. Sometimes, laser therapy is used alone, but it is often associated with surgery, chemotherapy, or radiation therapy. Lasers can close the nerve endings to relieve postoperative pain and seal the vessels of lymph to decrease swelling and the growth of tumor cells. ${ }^{2}$

As it is shown in Table 1, among the commonly used lasers are the erbium-doped yttrium aluminium garnet (Er:YAG) laser, ${ }^{3}$ the diode laser, the argon laser, the neodymium-doped yttrium-aluminum-garnet (Nd:YAG) solid state laser, ${ }^{4}$ and the CO2-gas laser. ${ }^{5}$ These lasers penetrate only at short distances in the tissue and result in fine and precise cuts in surgery. Laser technology was introduced by an Austrian neurosurgeon in 1976 to the neurosurgical community.

Lasers are used for surgical or non-contact surgical applications. In the first case, laser radiation heats a special surgical tip, which in turn is used for tissue excision through thermal conduction. Diode lasers are suitable for this operation method. Alternatively, in a noncontact mode, the laser source wavelength is selected to use high amounts of water in most soft tissues. Thuliumdoped fiber lasers, erbium-doped fiber lasers, and MidIR hybrid lasers are suitable for this operation method. ${ }^{6}$ Multiple systems of lasers are studied in some fields of medicine such as cancer treatment and tumor ablation, brain surgeries, epilepsy, cardiology and atrial fibrillation, lithotripsy, dermatology, skin rejuvenation, and lipolysis (see Figure 1). The energy of laser is a safe and effective tool for treating various cancers and the ablation of abnormal conductive pathways, for many reconstructive procedures and cosmetics. ${ }^{7}$ Due to advances in application of laser in surgery and its beneficial features, this review is planned to provide new perspective about usage of laser in surgery. 
Table 1. The Various Types of Lasers Used in Surgery

\begin{tabular}{lcc}
\hline Laser & Wavelength $(\mathbf{n m})$ & Absorption Chromophore \\
\hline Er:YAG & 2940 & Water \\
Diode & $630-980$ & Pigment, water (range) \\
Argon & $350-514$ & Pigment, hemoglobin \\
Nd:YAG & 1064 & Pigment, proteins \\
$\mathrm{CO}_{2}$ & 10600 & Water \\
\hline
\end{tabular}

\section{Methods}

"Laser", "surgery", and "beneficial" were the main keywords that were searched in NCBI and Google Scholar. The titles in English were studied and the suitable abstracts were selected. Finally, the full text of the intended documents was extracted. The time of search was considered by 2019.

\section{Cancer Treatment and Tumor Ablation Surgery}

Lasers today are safe methods for treating various cancers in organ systems. Laser ablation techniques have been successfully and widely used to treat superficial gastrointestinal cancers such as superficial esophageal and early gastric cancers, colorectal adenoma, and highgrade Barrett's esophagus. ${ }^{8}$ Laser photodynamic therapy is an effective treatment for specific types of lung cancer lesions. $^{9}$ Direct laser ablation through its photochemical and photothermal effects has been used to directly kill cancer cells. Photochemical reactions eventually produce toxic radicals and cause tissue death, cause stress on the tissue and fragmentation, and induce warming, blood coagulation, and cell death. ${ }^{10}$ Nearly a century ago, the photodynamic method was developed to target the tumor cells more precisely. This treatment involves the use of a photosynthetic drug followed by subsequent illumination of the desired area with visible light proportional to the absorption wavelength of the photosynthetic drug. ${ }^{11}$ The photosynthesizer, which first forms a single excited state and then a triplet state, generates reactive oxygen species which are destructive to neoplastic cells. ${ }^{12}$ Selective photothermal therapy uses the best "light absorbed dyes" to enhance laser inducing destruction of tumor cells. ${ }^{13}$

\section{Brain Surgery}

Surgical excision is the first treatment for malignant brain tumors; then chemotherapy and radiation therapy are done. However, glioblastoma surgery causes irreversible neurologic deficits, but it improves survival compared to chemotherapy and radiation alone. ${ }^{14}$ Some patients do not become candidates for surgery because of their

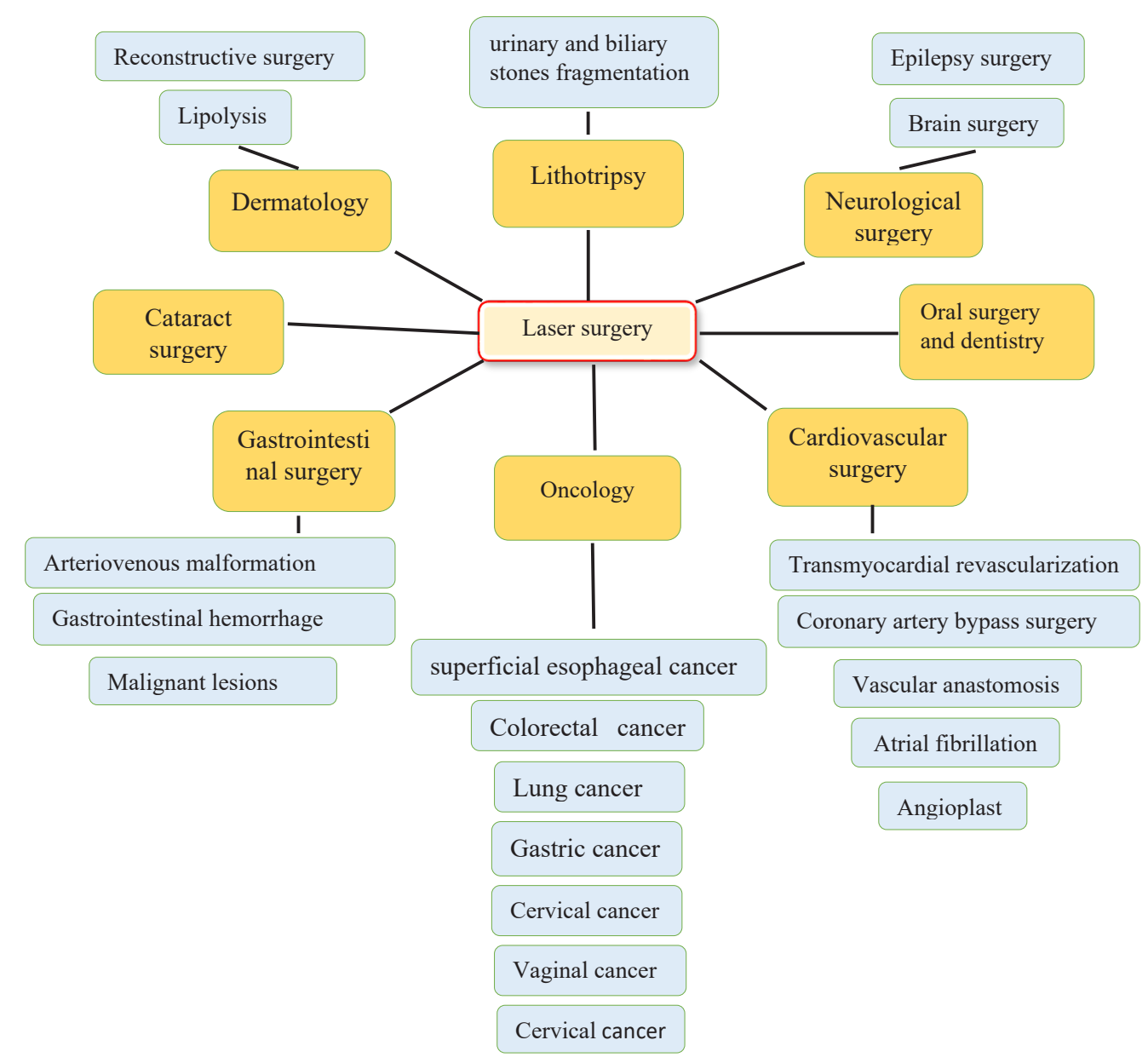

Figure 1. Schematic Representation of Laser Applications in Surgeries. 
multiple comorbidities. In addition, the presence of deep lesions, accompanying symptoms, low functional scores, and general anesthesia incapacity are considered as other limitations on surgical removal, so survival is limited. Radiosurgery is a low-risk invasive percutaneous alternative to brain metastases treatment with an $80 \%$ $90 \%$ local control rate over metastatic lesions. ${ }^{14,15}$ Recent advancement in laser interstitial thermal therapy (LITT) has improved the efficiency and safety of this method. LITT is a low-risk invasive percutaneous procedure that directs light energy through the fibropathic catheter to target in the tissue which leads to selective thermal ablation of malignant and benign lesions.

In 1983, Bown described LITT $^{16}$ and Sugiyama, in 1990, applied LITT in treating the brain lesions. ${ }^{17}$ LITT uses Nd: YAG lasers, which have a special tip for making and emitting light that prevents tissue carbonization (because carbon detoxification prevents light from being transmitted through the tissue). By using MR thermometry, dosage and resulting tissue temperature can be monitored. During surgery, real-time MRI produces the brain's living temperature map. This allows continually monitoring brain tissue temperatures and ensures that laser-induced damage is effectively located on the tumor and is restricted to the healthy tissue surrounding the tumor.

LITT is primarily used in tumor surgery ${ }^{18}$ and chronic pain ${ }^{19}$ and is a safe soothing alternative to highgrade malignant glioma ${ }^{20,21}$ and recurrent metastatic lesions. ${ }^{22,23}$ LITT is also used to treat many brain lesions including epilepsy, ${ }^{24,25}$ radiation necrosis, ${ }^{26,27}$ and refractory cerebral edema ${ }^{28}$ and tumors such as meningioma, ependymoma, primitive neuroectodermal tumor, chordoma, and hemangioblastoma. ${ }^{20,29}$ LITT produces low-risk invasive demolition of soft tissue pathology compared to other stereotactic procedures like radiofrequency thermocoagulation, gamma knife, and focused ultrasound. In addition, damage to the areas of the cerebral cortex during deep lesions can be minimized and completely prevented, and the treatment of epileptic foci near the scattered or even critical areas of the brain is possible. This method requires only a small incision and puncture to guide the laser fiber, so the treatment does not involve a craniotomy and is considered minimally invasive. The procedure typically lasts 3-4 hours and most patients are discharged the next day. ${ }^{18}$

\section{Epilepsy Surgery}

Pharmacologic treatment is one of the therapeutic methods with about $70 \%$ efficacy in treating epilepsy. ${ }^{30}$ Epilepsy surgery is an effective and safe treatment tool for symptomatic and focal epilepsies. ${ }^{31,32}$

Epilepsy surgery has some limitations; for example, deep-based targets can only be achieved by removing overlying brain tissue, and there are persistent neurologic and cognitive deficits and adverse effects on postoperative outcomes. Particularly, it affects cognitive outcomes. ${ }^{33,34}$ In addition, patients who have multiple epilepsy foci are excluded from surgery. Stereotactic surgical techniques represent innovative solutions and significant expansion of the neurosurgical tools. LITT is an innovative procedure in the field of stereotactic epilepsy surgery and it is an important instrument in the neurosurgical toolbox. Besides other stereotactic innovative methods such as radiofrequency thermocoagulation, gamma knife, and attentive ultrasound, LITT produces low-risk invasive demolition of soft tissue pathology, which is especially important for epilepsy resections. Unlike standard surgeries, craniotomy just needs a small trepanation. When accessing deep lesions, damage to the cortical areas may be completely avoided or minimized and treating epileptic foci near eloquent and even critical areas of the brain becomes possible. ${ }^{35}$

\section{Cardiovascular Surgery}

Angioplasty and coronary artery bypass surgery and medications are treatment approaches that improve and increase blood flow through the coronary arteries. When these therapeutic methods are depleted, the patient has no alternative to surgery except for the limited cases of heart transplantation. Without a viable alternative to surgery, the patient is generally treated with therapeutic drugs, often along with significant lifestyle restrictions. Transmyocardial laser revascularization (TMLR), laser vascular anastomosis, and laser angioplasty in peripheral arterial diseases are the new methods that improve blood flow to the heart areas which are not treated by angioplasty or surgery. In the cardiovascular surgery fields, laser applications are very rare throughout the world. ${ }^{36}$

TMLR is performed as a method in ischemic heart disease with areas that cannot be bypassed through a small split in the left of the chest between the ribs (thoracotomy) under general anesthesia with coronary bypass surgery or alone. It is the only treatment method for severe angina and is used as a supplementary method for coronary artery bypass grafting (CABG). In TMLR, the $\mathrm{CO} 2$ laser or the Ho:YAG laser is delivered directly to the target areas of the heart muscle. ${ }^{37}$

In TMLR, angina relief is more important than maximal medical treatment for coronary artery disease that is not revascularized. Combining CABG with TMLR has led to the improvement of symptoms and no additional risk. Angiogenesis is a possible mechanism in which TMLR has benefited from interacting with tissue. After TMLR, perfusion and concomitant improvement in myocardial function have been observed. ${ }^{38,39}$ Using clamps or staples in vascular anastomoses quickly works, but it causes more vascular damage than normal vessels. In many ways, considerable force is required to bend the straps or clamps. Some disadvantages are the high cost and limited size. Using fibrin and cyanoacrylate glues is very easy and time-saving. However, they require using additional 
sutures for stopping the formation of aneurysm. Most importantly, they cause anaphylactic and allergic reactions. Extra luminescent rings may seem appropriate in cardiac surgery, but one may have difficulty adjusting the diameter in vascular surgery. Only a few number of ring diameters are available. Low openness is the important disadvantage of intrauterine stents for vascular anastomosis. ${ }^{40}$

In laser bonding, energy through the laser changes the protein structure of the tissue and consequently is repaired by cross-linking the proteins. Main disadvantage of sutured anastomoses is the response of vessel wall to the external material of the applied suture. This external body reaction from the media and intima may provide myointimal hyperplasia. ${ }^{41}$

Laser-assisted vascular anastomosis (LAVA) does not require more or less optimal sutures. When simultaneously preventing thermal damage to the interior and environment caused by laser energy, it may be expected to have less hyperactivity at the site of anastomosis. Unlike other options, diagonal mismatches and toxic reactions in LAVA are not problematic. However, nature of the vessel walls is important. There is a perfect uniformity of intima versus intima without wrinkling. ${ }^{42}$

Laser angioplasty by using argon laser opens the obstructive arterial lumen. Peripheral arterial laser angioplasty under local anesthesia is performed in the inferior area beneath angioscopic guidance. Laser coronary angioplasty is also performed concurrently at the time of CABG for the patient with coronary stenosis. ${ }^{43,44}$ Clinically excellent long-term results have been obtained in the peripheral artery and coronary laser angioplasty. There have not been complications with the laser. Therefore, the possibility of laser application has been confirmed and laser angioplasty is recommended for patients with atherosclerotic changes, especially for small vessels. ${ }^{45}$ The LAVA vote has used different lasers such as the Nd:YAG, diode laser and $\mathrm{CO}_{2}$ laser. These lasers are used, along with various types of protein mixture used as weld and/or dyes, to make an anastomosis with enough potency to resist physiological changes in blood pressure.

The laser balloon catheter, the commonly endoscopic ablation method, is used for treating the atrial fibrillation. The diode laser that is located in the central lumen with a wavelength of $980 \mathrm{~nm}$ carries out ablation. The energy of laser emits at 90 degrees to the catheter shaft cover and allows circular ablation around each pulmonary veins. Deuterium oxide does not absorb the laser, then it permeates through tissue behind the endothelium and water molecules absorb it and cause heat-shock and coagulation necrosis. Delivered energy can be described by varying the power (to $5.5 \mathrm{~W}$ ) at a set of predetermined levels. ${ }^{46}$ Depending on which wall of cardiac is targeted, the energy levels change. ${ }^{47}$ The Nd:YAG lasers are usually used for this aim. ${ }^{48}$
By comparing the effects of various levels of energy, some studies indicate that using higher levels of energy increases pulmonary vein isolation with lower rates of recurrent atrial fibrillation and no compromise on safety. ${ }^{49,50}$ Recently, endovascular interventions such as atherectomy and balloon angioplasty have been clinically performed to treat peripheral atheromatous plaques and coronary arteries.

\section{Laser Lithotripsy}

Laser lithotripsy is a commonly accepted method for the fragmentation of urinary and biliary stones. ${ }^{51}$ Lasers with a photochemical device can perform lithotripsy and photothermal effect. Green light at $504 \mathrm{~nm}$ is produced and absorbed mostly by the yellow-colored urinary calculi. It can be safely used without damaging the surrounding tissues. ${ }^{3,52,53}$ This stone absorbs energy through the laser; excited ions can build up around the stone, creating a shock wave to break the stone into fragments. ${ }^{54}$ This laser is inefficient against colorless and non-absorbable compounds such as those consisting of cysteine, so photosynthetic sensors have been successfully used as irrigation and absorbent fluids to initiate the fragmentation process. ${ }^{55}$ The Q-switched Nd: YAG laser uses this mechanism to perform lithotripsy and generate a larger shock wave. ${ }^{56}$ The long-pulsed holmium:YAG laser, which makes light at a $2100 \mathrm{~nm}$ wavelength with extreme absorption by water, mostly uses a photothermal process to break up calculi. ${ }^{57}$ The peripheral fluid is heated after the absorption of energy. Some created steam separates from the water and cause fragmentation. ${ }^{3}$ Ho:YAG laser lithotripsy is the most effective endoscopic method with the higher rates of stone fragmentation for treating ureteral stones compared to pneumatic lithotripsy. Also, it is safe and efficacious and works more desirable than other methods. Furthermore, it is used for the fragmentation of biliary stones. ${ }^{58,59}$

\section{Cataract Surgery}

Ophthalmology has been at the head of using lasers and laser types have been used for over 50 years. ${ }^{60}$ Ophthalmic lasers work at a specific predetermined wavelength, energy, duration, pulse pattern, spot size and repetition rate. This allows the photons to enter the coherent and monochromatic laser beam phase to achieve the identical place and the same time in the target tissue. Therefore, altering these parameters makes different absorption in different tissues at various depths and biological effects, and any problem inside the eye is targeted by laser. Many lasers utilize molecular vibration, which produces local thermal effects such as photocoagulation (e.g. the argon laser). Other lasers such as excimer lasers are utilized in imaging and others such as Nd: YAG lasers are applied in refractive surgery by optical methods. ${ }^{61-64}$

Laser surgery is usually used on the eye to correct near and far-sightedness in vision. Femtosecond 
laser (FSL) cataract surgery is highly popular due to its better predictability and consistency for corneal incisions and anterior capsulorhexis outcome. These results subsequently make the energy and time of phacoemulsification less used which is accompanied with reduced corneal edema. FSL allows for better circulation of capsule overlap, the anterior capsulotomy, intraocular lens placement (IOL) and central IOL. All of these advantages lead to promotion of refractive and visual features of eye in the short term. The complication rate is low and is reduced by the experience of the surgeon. ${ }^{65}$

\section{Endoscopic Gastrointestinal Surgery}

The first uses of endoscopic lasers in humans were in the early 1970s after the development of flexible fibers for laser energy transfer. It seems the minimal risks led to its applications across the gastrointestinal tract. The laser coagulant effect on gastrointestinal bleeding and the treatment of benign small mucosal lesions and the positive effects of the Nd: YAG laser on the tissue make the lasers useful in the soothing treatment for malignant gastrointestinal disorders and the incision treatment for anatomical lesions such as stenosis or cysts. New laser methods that can be tuned to a wide range of electromagnetic spectrum, new optical fiber transmission systems with specialized tips, and new tissue sensing techniques for laser energy suggest that endoscopic lasers should continue to be used as innovative application..$^{1,66}$

Endoscopy detects gastrointestinal tumors at the early stage but achieving a less invasive diagnostic method is the aim of medicine. Lasers can be utilized as a less invasive diagnostic method for gastrointestinal detection. ${ }^{67}$

The thermal laser is a tool which is designed to assist the endoscopy of gastrointestinal cancers in an advanced stage. Interstitial laser photocoagulation is effective in the treatment of liver metastases. The most important new applications of lasers to the gastrointestinal tract are photodynamic therapies, especially the treatment of endoscopic dysplasia and small tumors in the gastrointestinal tract and pancreas. Light-based "optical" methods make accurate and faster detection possible. Recent methods are in the early stages of clinical trials, but if they are successful, optical detection can play a critical role in gastrointestinal function. ${ }^{68}$

\section{Oral Surgery}

Recent developments in laser technology have broadened the clinical use of lasers in dentistry and oral and facial cosmetic surgeries. $\mathrm{CO}_{2}$, Er:YAG, Diode and Nd:YAG are common lasers that are used in oral surgeries. Also, in assisting the procedures of disinfection and healing, low-level lasers are applied. Oral mucosa, oral benign lesions, oral cavity cancer, and excisional biopsy are a number of oral diseases treated by laser technology. The treatment of patients with oral mucosa lesions represents a therapeutic challenge. Laser therapy seems to be an effective alternative treatment for relieving the symptoms of the diseases. ${ }^{69}$

\section{Dermatology, Lipolysis and Reconstructive Surgery}

The specific properties of lasers in target structures and tissue layers have made them an important method for reconstructive surgery and anti-aging treatment by inducing new collagen formation systems using $\mathrm{CO}_{2}$ and Er: YAG lasers to target specific portions of the dermis. These systems significantly destroy the epidermis and cause side effects such as infection and erythema. Nonexcitation lasers such as Nd: YAG and diodes mainly emitted by infra-red light are best used to overcome these problems. These systems target the water in the dermis, which heats the collagen in the process and causes it to regenerate. ${ }^{70}$ A system that cools the epidermis, prevents water evaporation and consequently external scar production. $^{71}$

Laser-assisted lipolysis has become an increasingly popular method of cosmetic surgery that uses optical fiber because the smaller cannula produces smaller incisions resulting in less bleeding and less scar formation. Lasers with a wavelength of $920 \mathrm{~nm}$ have the lowest absorption coefficient in adipose tissue and therefore penetrate into deeper layers of tissue, but lasers with a wavelength in the range of 1320-1444 $\mathrm{nm}$ have the highest absorption coefficient in adipose tissue and thus allow greater penetration. ${ }^{70} \mathrm{Nd}$ : YAG lasers are more commonly used in lipolysis because application of these types of lasers alters absorption of energy and average temperature different amount of the fat absorption coefficient relative to the other tissue. In this method; less tissue damage as well as the coagulation of small blood vessels ${ }^{71}$ and a significant decrease in blood loss (54\%) compared to traditional methods are reported. ${ }^{72}$

The ability of lasers to target pathologic vessels selectively makes them a main source for treating the vascular defects (e.g. wine port stains). Before laser treatment, there were not many treatment methods for these abnormalities. Lasers, which are preferably absorbed by hemoglobin rather than melanin, are now used for this purpose and the trauma enters the epidermis slightly. Larger wavelength lasers and their ability to penetrate deeper into tissue have recently been introduced..$^{73-75}$

\section{Conclusion}

The finding from the present review indicates that laser surgery is spread vastly in medicine. This approach is associated with less bleeding, short time of recovery after surgery, and less side effects. High cost and its dependence on a specialist surgeon, applying of suitable set up of laser, and also finding standard laser devices are among the considerable difficulties with laser application in surgery.

\section{Ethical Considerations}

Not applicable. 


\section{Conflict of Interests}

The authors declare no conflict of interest.

\section{References}

1. Hunter JG, Bowers JH, Burt RW, Sullivan JJ, Stevens SL, Dixon JA. Lasers in endoscopic gastrointestinal surgery. Am J Surg. 1984;148(6):736-41. doi: 10.1016/00029610(84)90427-6.

2. Wilkinson JM, Cozine EW, Khan AR, Kahn AR. Refractive Eye Surgery: Helping Patients Make Informed Decisions About LASIK. Am Fam Physician. 2017;95(10):637-44.

3. Adams DH. Holmium: YAG laser and pulsed dye laser: a cost comparison. Lasers Surg Med. 1997;21(1):2931. doi: 10.1002/(sici)1096-9101(1997)21:1<29::aid$\operatorname{lsm} 5>3.0 . c 0 ; 2-\#$.

4. Halldórsson TH, Rother W, Langerholc J, Frank FJ. Theoretical and experimental investigations prove Nd: YAG laser treatment to be safe. Lasers Surg Med. 1981;1(3):25362. doi: 10.1002/lsm.1900010309.

5. Omi T, Numano K. The role of the $\mathrm{CO} 2$ laser and fractional CO2 laser in dermatology. Laser Ther. 2014;23(1):49-60. doi: 10.5978/islsm.14-RE-01.

6. Fried NM, Irby PB. Advances in laser technology and fibre-optic delivery systems in lithotripsy. Nat Rev Urol. 2018;15(9):563-73. doi: 10.1038/s41585-018-0035-8.

7. Parker S. Verifiable CPD paper: Introduction, history of lasers and laser light production. Br Dent J. 2007;202(1):2131. doi: 10.1038/bdj.2006.113.

8. Muguruma N, Okamoto K, Kimura T, Kishi K, Okahisa $\mathrm{T}$, Okamura S, et al. Endoscopic ablation therapy for gastrointestinal superficial neoplasia. Dig Endosc. 2012;24(3):139-49. doi: 10.1111/j.1443-1661.2011.01227.x.

9. Ikeda N, Usuda J, Kato H, Ishizumi T, Ichinose S, Otani K, et al. New aspects of photodynamic therapy for central type early stage lung cancer. Lasers Surg Med. 2011;43(7):74954. doi: 10.1002/lsm.21091.

10. Thomsen S. Pathologic analysis of photothermal and photomechanical effects of laser-tissue interactions. Photochem Photobiol. 1991;53(6):825-35. doi: 10.1111/ j.1751-1097.1991.tb09897.x.

11. Mroz P, Yaroslavsky A, Kharkwal GB, Hamblin MR. Cell death pathways in photodynamic therapy of cancer. Cancers (Basel). 2011;3(2):2516-39. doi: 10.3390/cancers3022516.

12. Abrahamse H, Hamblin MR. New photosensitizers for photodynamic therapy. Biochem J. 2016;473(4):347-64. doi: 10.1042/BJ20150942.

13. Chen WR, Adams RL, Heaton S, Dickey DT, Bartels KE, Nordquist RE. Chromophore-enhanced laser-tumor tissue photothermal interaction using an 808-nm diode laser. Cancer lett. 1995;88(1):15-9. doi: 10.1016/03043835(94)03609-m.

14. Loeffler JS, Barker FG, Chapman PH. Role of radiosurgery in the management of central nervous system metastases. Cancer Chemother Pharmacol. 1999;43(1):S11-S4. doi: 10.1007/s002800051092.

15. Mondschein J, Kahn E, Chakravarthy A, Cmelak A, Sosman J, Thompson R, et al. Stereotactic radiosurgery plus whole brain radiation therapy vs. stereotactic radiosurgery alone in the treatment of brain metastases from malignant melanoma. Int J Radiat Oncol Biol Phys.
2010;78(3):S262-S3.

16. Bown SG. Phototherapy in tumors. World J Surg. 1983;7(6):700-9. doi: 10.1007/bf01655209.

17. Sugiyama K, Sakai T, Fujishima I, Ryu H, Uemura K, Yokoyama T. Stereotactic interstitial laser-hyperthermia using Nd-YAG laser. Stereotact Funct Neurosurg. 1990;54(18):501-5. doi: 10.1159/000100263.

18. Medvid R, Ruiz A, Komotar RJ, Jagid J, Ivan M, Quencer R, et al. Current applications of MRI-guided laser interstitial thermal therapy in the treatment of brain neoplasms and epilepsy: a radiologic and neurosurgical overview. AJNR Am J Neuroradiol. 2015;36(11):1998-2006. doi: 10.3174/ ajnr.A4362.

19. Patel P, Patel NV, Danish SF. Intracranial MR-guided laser-induced thermal therapy: single-center experience with the Visualase thermal therapy system. J Neurosurg. 2016;125(4):853-60. doi: 10.3171/2015.7.JNS15244.

20. Mohammadi AM, Schroeder JL. Laser interstitial thermal therapy in treatment of brain tumors-the NeuroBlate System. Expert Rev Med Devices. 2014;11(2):109-19. doi: $10.1586 / 17434440.2014 .882225$.

21. Jethwa PR, Barrese JC, Gowda A, Shetty A, Danish SF. Magnetic resonance thermometry-guided laser-induced thermal therapy for intracranial neoplasms: initial experience. Neurosurgery. 2012;71(1):133-45. doi: 10.1227/ NEU.0b013e31826101d4.

22. Carpentier A, McNichols RJ, Stafford RJ, Guichard JP, Reizine D, Delaloge S, et al. Laser thermal therapy: Realtime MRI-guided and computer-controlled procedures for metastatic brain tumors. Lasers Surg Med. 2011;43(10):94350. doi: 10.1002/lsm.21138.

23. Schulze P, Vitzthum H, Goldammer A, Schneider J, Schober R. Laser-induced thermotherapy of neoplastic lesions in the brain-underlying tissue alterations, MRImonitoring and clinical applicability. Acta Neurochir (Wien). 2004;146(8):803-12. doi: 10.1007/s00701-0040293-5.

24. Hawasli AH, Ray WZ, Murphy RK, Dacey Jr RG, Leuthardt EC. Magnetic resonance imaging-guided focused laser interstitial thermal therapy for subinsular metastatic adenocarcinoma: technical case report. Neurosurgery. 2011;70(2):332-7. doi: 10.1227/NEU.0b013e318232fc90.

25. Willie JT, Laxpati NG, Drane DL, Gowda A, Appin C, Hao $\mathrm{C}$, et al. Real-time magnetic resonance-guided stereotactic laser amygdalohippocampotomy for mesial temporal lobe epilepsy. Neurosurgery. 2014;74(6):569-85. doi: 10.1227/ NEU.0000000000000343.

26. Torres-Reveron J, Tomasiewicz HC, Shetty A, Amankulor NM, Chiang VL. Stereotactic laser induced thermotherapy (LITT): a novel treatment for brain lesions regrowing after radiosurgery. J Neurooncol. 2013;113(3):495-503. doi: 10.1007/s11060-013-1142-2.

27. Rahmathulla G, Recinos PF, Valerio JE, Chao S, Barnett GH. Laser interstitial thermal therapy for focal cerebral radiation necrosis: a case report and literature review. Stereotact Funct Neurosurg. 2012;90(3):192-200. doi: $10.1159 / 000338251$.

28. Fabiano AJ, Alberico RA. Laser-interstitial thermal therapy for refractory cerebral edema from post-radiosurgery metastasis. World Neurosurg. 2014;81(3-4):652.e1-4. doi: 10.1016/j.wneu.2013.10.034. 
29. Jethwa PR, Lee JH, Assina R, Keller IA, Danish SF. Treatment of a supratentorial primitive neuroectodermal tumor using magnetic resonance-guided laser-induced thermal therapy. J Neurosurg Pediatr. 2011;8(5):468-75. doi: 10.3171/2011.8.PEDS11148.

30. Kwan P, Brodie MJ. Early identification of refractory epilepsy. N Engl J Med. 2000;342(5):314-9. doi: 10.1056/ NEJM200002033420503.

31. Liu SY, Yang XL, Chen B, Hou Z, An N, Yang MH, et al. Clinical outcomes and quality of life following surgical treatment for refractory epilepsy: a systematic review and meta-analysis. Medicine (Baltimore). 2015;94(6):e500. doi: 10.1097/MD.0000000000000500.

32. Mathon B, Ulvin LB, Adam C, Baulac M, Dupont S, Navarro $\mathrm{V}$, et al. Surgical treatment for mesial temporal lobe epilepsy associated with hippocampal sclerosis. Rev Neurol (Paris). 2015;171(3):315-25. doi: 10.1016/j.neurol.2015.01.561.

33. Helmstaedter C, Van Roost D, Clusmann H, Urbach H, Elger C, Schramm J. Collateral brain damage, a potential source of cognitive impairment after selective surgery for control of mesial temporal lobe epilepsy. J Neurol Neurosurg Psychiatry. 2004;75(2):323-6.

34. Helmstaedter C, Richter S, Röske S, Oltmanns F, Schramm J, Lehmann TN. Differential effects of temporal pole resection with amygdalohippocampectomy versus selective amygdalohippocampectomy on material-specific memory in patients with mesial temporal lobe epilepsy. Epilepsia. 2008;49(1):88-97. doi: 10.1111/j.1528-1167.2007.01386.x.

35. Hoppe C, Witt J-A, Helmstaedter C, Gasser T, Vatter H, Elger CE. Laser interstitial thermotherapy (LiTT) in epilepsy surgery. Seizure. 2017;48:45-52. doi: 10.1016/j. seizure.2017.04.002.

36. Okada M, Yoshida M, Tsuji Y, Horii H. Clinical application of laser treatment for cardiovascular surgery. Laser Ther. 2011;20(3):217-32. doi: 10.5978/islsm.20.217.

37. Mirhoseini M, Shelgikar S, Cayton MM. New concepts in revascularization of the myocardium. Ann Thorac Surg. 1988;45(4):415-20. doi: 10.1016/s0003-4975(98)90015-7.

38. Horvath KA, Cohn LH, Cooley DA, Crew JR, Frazier OH, Griffith BP, et al. Transmyocardial laser revascularization: results of a multicenter trial with transmyocardial laser revascularization used as sole therapy for end-stage coronary artery disease. I Thorac Cardiovasc Surg. 1997;113(4):645-54. doi: 10.1016/S0022-5223(97)70221-6.

39. Allen KB, Dowling RD, Fudge TL, Schoettle GP, Selinger SL, Gangahar DM, et al. Comparison of transmyocardial revascularization with medical therapy in patients with refractory angina. N Engl J Med. 1999;341(14):1029-36. doi: 10.1056/NEJM199909303411403.

40. Wolf-de Jonge I, Beek J, Balm R. 25 years of laser assisted vascular anastomosis (LAVA): what have we learned? Eur J Vasc Endovasc Surg. 2004;27(5):466-76. doi: 10.1016/j. ejvs.2004.02.021

41. Quigley MR, Bailes JE, Kwaan HC, Cerullo LJ, Block S. Comparison of myointimal hyperplasia in laser-assisted and suture anastomosed arteries: a preliminary report. J Vasc Surg. 1986;4(3):217-9. doi: 10.1067/mva.1986. avs0040217.

42. Birch J, Bell PR. Methylene blue soldered microvascular anastomoses in vivo. Eur J Vasc Endovasc Surg. 2002;23(4):325-30. doi: 10.1053/ejvs.2001.1601.
43. Okada M, Yoshida M, Tsuji Y. Clinical experience of endovascular laser intervention in cardiovascular disease. J Clin Laser Med Surg. 1998;16(5):249-54. doi: 10.1089/ clm.1998.16.249.

44. Okada M, Yoshida M, Tsuji Y. Clinical experience of laser angioplasty for the cardiovascular disease. Diagn Ther Endosc. 1995;2(1):11-8. doi: 10.1155/DTE.2.11.

45. Powell RJ. Endovascular treatment in the superficial femoral artery: which devices, where? Semin Vasc Surg. 2008;21(4):180-5. doi: 10.1053/j.semvascsurg.2008.11.003.

46. Bordignon S, Chun KRJ, Gunawardene M, Schulte-Hahn B, Nowak B, Fuernkranz A, et al. Endoscopic ablation systems. Expert Rev Med Devices. 2013;10(2):177-83. doi: 10.1586/erd.12.86.

47. Metzner A, Wissner E, Lin T, Ouyang F, Kuck KH. Balloon devices for atrial fibrillation therapy. Arrythm Electrophysiol Rev. 2015;4(1):58-61. doi: 10.15420/aer.2015.4.1.58.

48. Dörschel K, Müller G. The role of laser in cardiac surgery. Thorac Cardiovasc Surg. 1999;47(3):385-7. doi: 10.1055/s2007-1013206.

49. Metzner A, Wissner E, Schoonderwoerd B, Burchard A, Tilz R, Fürnkranz A, et al. The influence of varying energy settings on efficacy and safety of endoscopic pulmonary vein isolation. Heart Rhythm. 2012;9(9):1380-5. doi: 10.1016/j.hrthm.2012.03.059.

50. Bordignon S, Chun KRJ, Gunawardene M, Urban V, Kulikoglu M, Miehm K, et al. Energy titration strategies with the endoscopic ablation system: lessons from the high-dose vs. low-dose laser ablation study. Europace. 2012;15(5):685-9. doi: 10.1093/europace/eus352.

51. Dretler SP. Laser lithotripsy: a review of 20 years of research and clinical applications. Laser Surg Med.1988;8(4):341-56. doi: 10.1002/lsm.1900080403.

52. Chan KF, Joshua Pfefer T, Teichman JM, Welch AJ. A perspective on laser lithotripsy: the fragmentation processes. J Endourol. 2001;15(3):257-73. doi: 10.1089/089277901750161737.

53. Grasso M, Bagley D, Sullivan K. Pulsed dye laser lithotripsy-currently applied to urologic and biliary calculi. J Clin Laser Med Surg. 1991;9(5):355-9. doi: 10.1089/clm.1991.9.355.

54. Azadgoli B, Baker RY. Laser applications in surgery. Ann Transl Med. 2016;4(23):452. doi: 10.21037/atm.2016.11.51.

55. Tasca A, Cecchetti W, Zattoni F, Pagano F. Photosensitization of cystine stones to induce laser lithotripsy. J Urol. 1993;149(4):709-12. doi: 10.1016/s0022-5347(17)36189-x.

56. Rink K, Delacrétaz G, Salathé RP. Fragmentation process of current laser lithotriptors. Lasers Surg Med. 1995;16(2):13446. doi: 10.1002/lsm.1900160203.

57. Chan KF, Vassar GJ, Pfefer TJ, Teichman JM, Glickman RD, Weintraub ST, et al. Holmium: YAG laser lithotripsy: a dominant photothermal ablative mechanism with chemical decomposition of urinary calculi. Lasers Surg Med. 1999;25(1):22-37. doi: 10.1002/(sici)10969101(1999)25:1<22::aid-lsm4>3.0.co;2-6.

58. Cimino S, Favilla V, Russo GI, Saita A, Sortino G, Castelli T, et al. Pneumatic lithotripsy versus holmium: YAG laser lithotripsy for the treatment of single ureteral stones: a prospective, single-blinded study. Urol Int. 2014;92(4):46872. doi: $10.1159 / 000355828$.

59. Teichman JM. Laser lithotripsy. Curr Opin Urol. 
2002;12(4):305-9. doi: 10.1097/00042307-20020700000008.

60. Alio J. Refractive surgery today: is there innovation or stagnation? Eye Vis (Lond). 2014;1(1):4. doi: 10.1186/ s40662-014-0004-0.

61. Bressler NM, Beck RW, Ferris FL 3rd. Panretinal photocoagulation for proliferative diabetic retinopathy. $N$ Engl J Med. 2011;365(16):1520-6. doi: 10.1056/ NEJMct0908432.

62. McAlinden C, Moore JE. The change in internal aberrations following myopic corneal laser refractive surgery. Graefes Arch Clin Exp Ophthalmol. 2011;249(5):775-81. doi: 10.1007/s00417-010-1459-x.

63. McAlinden C, Moore J. Laser-assisted subepithelial keratectomy retreatment surgery. J Cataract Refract Surg. 2011;37(2):358-63. doi: 10.1016/j.jcrs.2010.11.009.

64. Weiblinger RP. Review of the clinical literature on the use of the Nd: YAG laser for posterior capsulotomy. J Cataract Refract Surg. 1986;12(2):162-70. doi: 10.1016/s08863350(86)80034-7.

65. Donaldson KE, Braga-Mele R, Cabot F, Davidson R, Dhaliwal DK, Hamilton R, et al. Femtosecond laser-assisted cataract surgery. J Cataract Refract Surg. 2013;39(11):175363. doi: 10.1016/j.jcrs.2013.09.002.

66. Berr F, Wiedmann M, Tannapfel A, Halm U, Kohlhaw KR, Schmidt F, et al. Photodynamic therapy for advanced bile duct cancer: evidence for improved palliation and extended survival. Hepatology. 2000;31(2):291-8. doi: 10.1002/hep.510310205.

67. Lovat LB, Mathou N, Thorpe SM, Gertner D, Sargeant
IR, Winslet MC, et al. 7048 Relief of dysphagia with self expanding metal stents is far from perfect. Gastrointest Endosc. 2000;51(4):AB254. doi: 10.1016/S00165107(00)14719-4.

68. Bown SG, Lovat LB. The biology of photodynamic therapy in the gastrointestinal tract. Gastrointest Endosc Clin N Am. 2000;10(3):533-50. doi: 10.1016/S1052-5157(18)30121-1.

69. Asnaashari M, Zadsirjan S. Application of laser in oral surgery. J Lasers Med Sci. 2014;5(3):97-107.

70. Majdabadi A, Abazari M. Study of interaction of laser with tissue using monte carlo method for $1064 \mathrm{~nm}$ neodymiumdoped yttrium aluminium garnet (Nd: YAG) laser. J Lasers Med Sci. 2015;6(1):22-7.

71. Lukac M, Vizintin Z, Zabkar J, Pirnat S. QCW pulsed Nd: YAG $1064 \mathrm{~nm}$ laser lipolysis. Journal of the Laser and Health Academy. 2009;4(1):24-34.

72. Abdelaal MM, Aboelatta YA. Comparison of blood loss in laser lipolysis vs traditional liposuction. Aesthet Surg J. 2014;34(6):907-12. doi: 10.1177/1090820X14536904.

73. Wu EC, Wong BJ. Lasers and optical technologies in facial plastic surgery. Arch Facial Plast Surg. 2008;10(6):381-90. doi: 10.1001/archfaci.10.6.381.

74. Kelly KM, Choi B, McFarlane S, Motosue A, Jung B, Khan $\mathrm{MH}$, et al. Description and analysis of treatments for port-wine stain birthmarks. Arch Facial Plast Surg. 2005;7(5):287-94. doi: 10.1001/archfaci.7.5.287.

75. Faurschou A, Olesen AB, Leonardi-Bee J, Haedersdal M. Lasers or light sources for treating port-wine stains. Cochrane Database Syst Rev. 2011;9(11):CD007152. doi: 10.1002/14651858.CD007152.pub2. 